\title{
Prevalence and distribution of human Plasmodium infection in Pakistan
}

\author{
Aamer A Khattak ${ }^{1}$, Meera Venkatesan²,3, Muhammad F Nadeem, ${ }^{4,5}$, Humayoon S Satti ${ }^{1}$, Adnan Yaqoob ${ }^{5}$, \\ Kathy Strauss ${ }^{2}$, Lubna Khatoon ${ }^{1}$, Salman A Malik ${ }^{1}$ and Christopher V Plowe $2,3^{*}$
}

\begin{abstract}
Background: Both Plasmodium vivax and Plasmodium falciparum are prevalent in Pakistan, yet up-to-date data on the epidemiology of malaria in Pakistan are not available. This study was undertaken to determine the current prevalence and distribution of Plasmodium species across the country.

Methods: A malariometric population survey was conducted in 2011 using blood samples collected from 801 febrile patients of all ages in four provinces and the capital city of Islamabad. Microscopically confirmed Plasmodium-positive blood samples were reconfirmed by polymerase chain reaction (PCR). Confirmed parasite-positive samples were subjected to species-specific PCR capable of detecting four species of human malaria.
\end{abstract}

Results: Of the 707 PCR-positive samples, 128 (18\%) were P. falciparum, 536 (76\%) were P. vivax, and 43 (6\%) were mixed P. falciparum and P. vivax. Ninety-four microscopy-positive samples were PCR-negative, and Plasmodium malariae and Plasmodium ovale were not detected. Prevalence of P. vivax ranged from $2.4 \%$ in Punjab Province to $10.8 \%$ in Sindh Province and prevalence of $P$. falciparum ranged from $0.1 \%$ in Islamabad to $3.8 \%$ in Balochistan.

Conclusions: Plasmodium infections in Pakistan are largely attributed to $P$. vivax but $P$. falciparum and mixed species infections are also prevalent. In addition, regional variation in the prevalence and species composition of malaria is high.

Keywords: Plasmodium falciparum, Plasmodium vivax, Malaria, Pakistan

\section{Background}

Ninety-five million of Pakistan's 161 million people, roughly $60 \%$ of Pakistan's population, live in malariaendemic regions [1,2]. After eradication efforts in the 1960s, malaria surged back to an epidemic level in the 1970s. In recent years, an uptick in malaria can be partially attributed to floods that affected approximately 20 million people in over 60 districts [2]. Despite a well-established malaria control programme, 500,000 malaria infections and 50,000 malaria-attributable deaths occur each year in Pakistan [3], with approximately $37 \%$ of cases estimated to occur in regions along the borders with Afghanistan and Iran [4].

Pakistan's climate ranges from tropical to temperate with dry conditions along the southern coast [5], and

\footnotetext{
* Correspondence: cplowe@medicine.umaryland.edu

${ }^{2}$ Howard Hughes Medical Institute/Center for Vaccine Development,

University of Maryland School of Medicine, Baltimore, MD, USA

${ }^{3}$ WorldWide Antimalarial Resistance Network Molecular Module, University of

Maryland School of Medicine, Baltimore, MD, USA

Full list of author information is available at the end of the article
}

elevation ranges from sea level to nearly 9,000 meters [6]. Plasmodium vivax (responsible for approximately $64 \%$ of infections) and Plasmodium falciparum (causing 36\% of infections) are the two prevalent Plasmodium species in Pakistan [7], and malaria is primarily found in the provinces of Khyber Pakhtunkhwa, Balochistan, Sindh and the Federally Administered Tribal Areas [8]. Malaria transmission is considered to be unstable, with major $P$. vivax transmission peaking from June to September and again in April to June, when relapses of infections acquired the previous season are observed [9]. The major transmission period for P. falciparum in Pakistan is between August and December [9].

Although the majority of malaria cases in Pakistan is caused by $P$. vivax, trends in the past few decades have indicated that $P$. falciparum infection is on the rise. The World Health Organization (WHO) reported that in Pakistan the proportion of malaria infections attributed to $P$. falciparum rose from $34 \%$ in 1987 to $54 \%$ in $1990[9,10]$. The frequency of $P$. falciparum among 
microscopy-positive cases rose from $45 \%$ in 1995 to $68 \%$ in 2006 in the city of Quetta in Balochistan province and in Jhangara city of Sindh province [11,12]. In 2010, 73,857 (31\%) of 240,591 total reported malaria cases in Pakistan were $P$. falciparum [13].

The rise of $P$. falciparum in parts of Pakistan may be partially attributable to failed treatment of chloroquineresistant infections [14]. Chloroquine resistance in $P$. falciparum was reported for the first time from Pakistan in 1984 and later confirmed as widespread [13,15-17]. A recent study found that $90 \%$ of $P$. falciparum samples collected in the provinces of Balochistan and Sindh carried the pfcrt $76 \mathrm{~T}$ allele responsible for conferring chloroquine resistance [18]. Although chloroquine is recommended only for treatment of $P$. vivax, $P$. falciparum infections are often treated with chloroquine, as presumptive diagnosis or empiric treatment is usually based on clinical symptoms in resource-limited countries like Pakistan [19].

The heavy influx and continued presence of refugees from Afghanistan, where P. falciparum is more prevalent, may also contribute to the increase of $P$. falciparum in Pakistan [20-22] potentiating clinical trials of falciparum malaria in the refugee populations in regions such as Khyber Pakhtunkhwa province [23]. Studies have indicated that refugees have low immunity and are more susceptible to malaria in Pakistan than are permanent residents $[10,24,25]$. These factors may lead to increased disease and transmission in the refugee population. Monitoring the distribution and burden of Plasmodium species in Pakistan as changes occur in both human and parasite populations is necessary to ensure appropriate treatment, particularly in situations where diagnosis by microscopy or species-specific rapid diagnostic tests is not available.

A handful of malaria epidemiological studies have been conducted in parts of Pakistan, but the assessment of the malaria burden on a national scale has been hindered by the lack of data from many areas [26]. One report of malariometric surveys conducted from 2005 to 2009 found both spatial and temporal variation in malaria endemicity. Malaria prevalence was highest in the Federally Administered Tribal Areas, followed by Balochistan and Khyber Pakhtunkhwa Provinces [4] (Figure 1), and over the five-year period malaria incidence was highest in 2009 [4]. The aim of this study was to provide a current report on malaria in Pakistan. Surveys were conducted in 2011 in 14 sites across four provinces as well as in the capital city of Islamabad to determine the prevalence of malaria infection among suspected cases

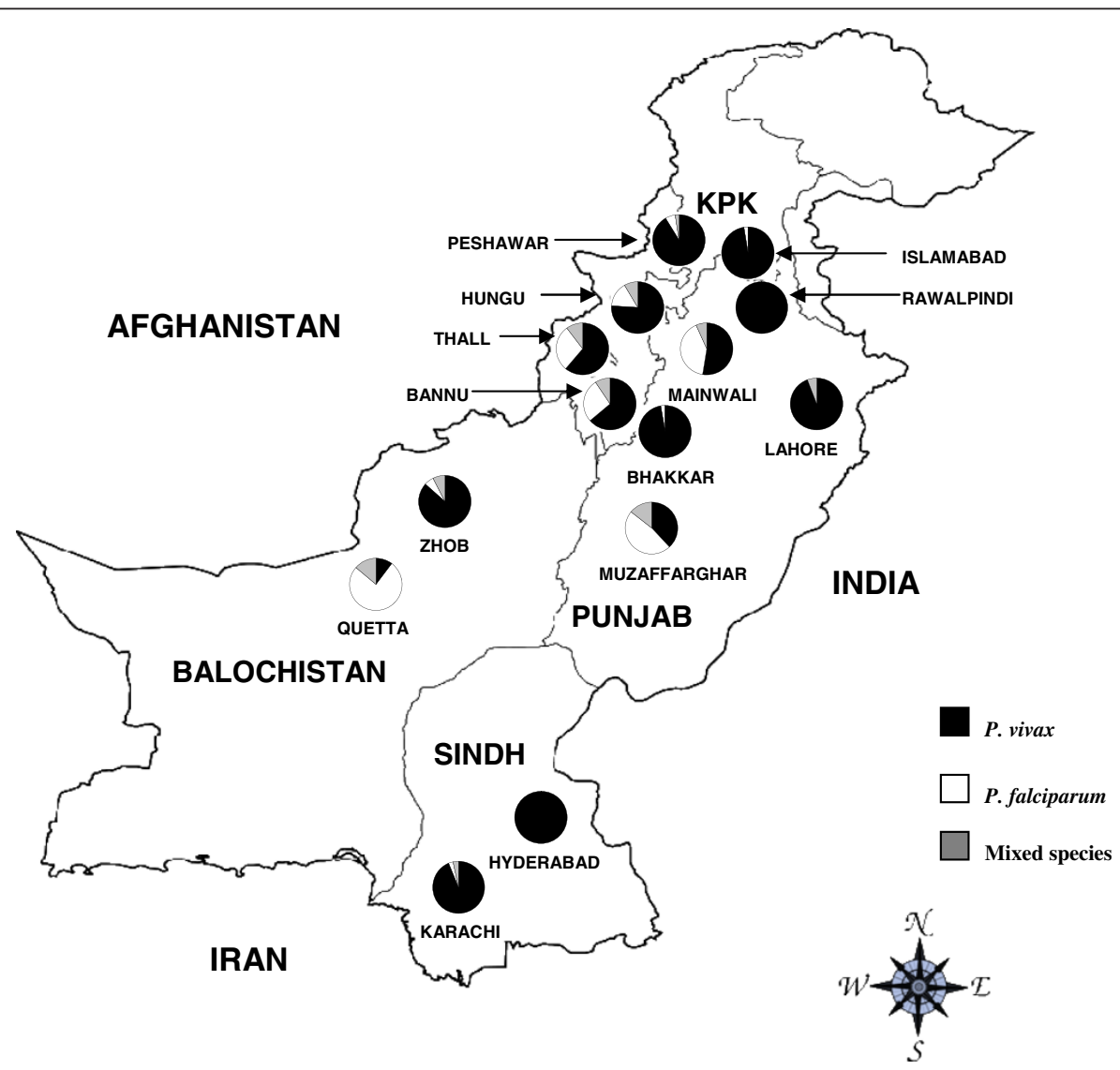

Figure 1 Sample sites and distribution of Plasmodium species across Pakistan, 2011. KPK: Khyber Pakhtunkhwa province. 
and to map the distribution of Plasmodium species across the country.

\section{Methods}

Government and private hospitals in 25 cities from four provinces with the highest burden of malaria representing all four provinces (Khyber Pakhtunkhwa province, Sindh province, Balochistan province and Punjab province) and a hospital in the capital city, Islamabad, were invited to participate in the molecular survey. Although the Federally Administered Tribal Areas have among the highest burdens of malaria in the country, they were excluded from this study because political instability and violence [27] make it difficult to establish sample collection. Of the facilities that were contacted, hospitals in 14 cities shared samples and were included in this study: Islamabad (Capital), Peshawar, Thall, Bannu and Hangu (Khyber Pakhtunkhwa province), Karachi and Hyderabad (Sindh province), Zhob and Quetta (Balochistan province), Rawalpindi, Bhakhar, Mainwali, Lahore and Muzaffargarhar (Punjab province) (Figure 1). Samples were collected during the peak malaria transmission season, between April and October 2011, at all sites. The study included patients of all age groups with malarial signs and symptoms (fever, chills, headache, sweats, fatigue, nausea and vomiting). The study was approved by the Institutional Review Board of Quaid-i-Azam University, Pakistan.

For patients giving informed consent, $3 \mathrm{ml}$ of intravenous blood was drawn into an EDTA tube by venepuncture and limited demographic information (patient age and gender) was recorded. Thick and thin films were stained with $10 \%$ Giemsa solution and examined at $100 \times$ under oil immersion. Smears were examined by a laboratory technician or technologist trained in malaria diagnosis according to $\mathrm{WHO}$ guidelines [28]. About $50 \mu \mathrm{l}$ of each blood sample from 801 malaria microscopypositive and 30 smear-negative samples was also applied to Whatman 3MM filter paper. Blood spots were air-dried overnight and stored in individual plastic bags with desiccant at room temperature. Remaining blood samples were stored at $-80^{\circ} \mathrm{C}$ on site at each hospital.

Molecular analysis was conducted at the University of Maryland School of Medicine, Baltimore, MD, USA. Parasite DNA was extracted from filter papers using the Qiagen DNA extraction kit (Qiagen, Valencia, CA, USA). Plasmodium species (P. vivax, P. falciparum, Plasmodium ovale and Plasmodium malariae) were detected by nested polymerase chain reaction (PCR) amplification of the small sub-unit ribosomal ribonucleic acid (ssrRNA) genes using the primers and thermal cycler conditions as described $[29,30]$. The amplified PCR products were visualized by $2-$ $2.5 \%$ agarose gel electrophoresis, stained with ethidium bromide and visualized using the Bio-Rad gel doc system (Bio-Rad Laboratories, Hercules, CA, USA).

\section{Results}

A total of 801 microscopy-positive samples was amplified by PCR along with positive and negative controls. By microscopy, $17 \%(\mathrm{n}=138)$ were identified as $P$. falciparum, $82 \%(\mathrm{n}=656)$ as $P$. vivax and $0.9 \%(\mathrm{n}=7)$ as mixed (Table 1). Nested PCR identified $18 \%(\mathrm{n}=128)$ as P. falciparum, $76 \%(\mathrm{n}=536)$ as $P$. vivax, $6 \%(\mathrm{n}=43)$ as mixed $P$. falciparum/P. vivax, and 94 samples as parasite-negative. $P$. malariae and $P$. ovale were not detected in any samples, and 27 of 30 microscopy-negative samples were parasitepositive by PCR.

Discrepancies between PCR and microscopy were identified for 36 mixed-species samples by PCR (10 characterized as $P$. falciparum monoinfection and 26 as $P$. vivax monoinfection by microscopy) and 94 parasite-negative samples by PCR (characterized as P. vivax (82), P. falciparum (11) and mixed species infection (1) by microscopy). Slides were not available for re-examination in the case of discrepancies between microscopy and PCR, but PCR was repeated and results confirmed for all 130 samples.

Cohen's kappa statistic to measure concordance between microscopy and PCR indicated that overall agreement for presence or absence of Plasmodium infection was high (kappa $=0.89$ ), although agreement on mixed species infections was low (kappa $=0.49)$ due to the identification of a number of mixed species infections by PCR as either $P$. vivax or $P$. falciparum monoinfections by microscopy. Agreement on diagnosis as $P$. falciparum was high (kappa $=0.94)$ while agreement for $P$. vivax was slightly lower (kappa $=0.82)$, owing to the classification of 120 samples as $P$. vivax-positive by microscopy that did not have a detectable infection by PCR.

The age of subjects ranged from two months to 75 years, with a median of 24 years (Table 2). Age did not vary significantly by province. Overall, nearly two-thirds $(64 \%)$ of the subjects were male. Males predominated in all study areas, ranging from $55 \%$ of subjects in Balochistan to $72 \%$ of subjects in Islamabad.

Of the 801 microscopy-positive samples, 707 PCRpositive malaria cases were detected at all sites (Table 3). Khyber Pakhtunkhwa had the highest number of cases at 325, followed by Punjab with 157 cases. The overall

Table 1 Microscopic and PCR-based diagnosis of Plasmodium infections in clinical isolates

\begin{tabular}{ccc}
\hline Species & Microscopy & PCR analysis \\
\hline Plasmodium falciparum & $138(17 \%)$ & $128(18 \%)$ \\
\hline Plasmodium vivax & $656(82 \%)$ & $536(76 \%)$ \\
\hline Mixed (P. falciparum + P. vivax) & $7(1 \%)$ & $43(6 \%)$ \\
\hline Plasmodium malariae & 0 & 0 \\
\hline Plasmodium ovale & 0 & 0 \\
\hline Negative & 0 & $94(12 \%)$ \\
\hline
\end{tabular}


Table 2 Gender and age distributions of subjects by province

\begin{tabular}{cccc}
\hline & $\begin{array}{c}\text { Males } \\
\text { N (\%) }\end{array}$ & $\begin{array}{c}\text { Females } \\
\text { N (\%) }\end{array}$ & $\begin{array}{c}\text { Age in years median } \\
\text { (Range) }\end{array}$ \\
\hline Balochistan & $52(55 \%)$ & $42(45 \%)$ & $29(4$ to 70$)$ \\
\hline Islamabad & $62(72 \%)$ & $23(28 \%)$ & $26(3$ to 75$)$ \\
\hline KPK & $231(63 \%)$ & $133(37 \%)$ & $22(0.3$ to 75$)$ \\
\hline Punjab & $126(64 \%)$ & $71(36 \%)$ & $24(0.4$ to 65$)$ \\
\hline Sindh & $38(62 \%)$ & $23(38 \%)$ & $28(0.3$ to 65$)$ \\
\hline
\end{tabular}

prevalence of Plasmodium in Pakistan among treatmentseeking patients with suspected malaria was $6.6 \%$ : 5\% $P$. vivax, $1.2 \%$ P. falciparum and $0.4 \%$ mixed P.vivax/ P. falciparum infections. Balochistan, Sindh and Khyber Pakhtunkhwa provinces exhibited the highest prevalence of total Plasmodium infections, at 12.4, 11.1 and $10.8 \%$, respectively (Table 3). Malaria prevalence in Punjab ranged from $1.7 \%$ in Lahore to $5.5 \%$ in Bhakkar cities. The capital city of Islamabad had an overall malaria prevalence of $4.6 \%$ (Table 3).

P. vivax was the predominant malaria species in most regions of the survey. However, P. falciparum was found in the majority of Plasmodium infections in Quetta city of Balochistan province, and Muzaffarghar of Punjab province and in about one-third to one-half of all malaria infections in three other sites: Mainwali in Punjab, and Hangu and Bannu near Khyber Pakhtunkhwa's Afghan border (Figure 1). Balochistan and Khyber Pakhtunkhwa provinces had the highest proportion of mixed $P$. falciparum/P. vivax infections, at 10 and $8 \%$, respectively. P. falciparum malaria was virtually absent from the other three Punjabi sites, as well as from both cities in Sindh province and from Islamabad city (Table 4).

\section{Discussion}

Malaria continues to be a serious public health problem in Pakistan. In 2008, 2.6 million malaria cases were reported nationwide with a mortality rate of 50,000 per year [13,31-33]. Over one million microscopy-confirmed malaria cases were reported from the Eastern Mediterranean region in 2010, 22\% of which came from Pakistan [13]. It has been difficult to accurately estimate the prevalence of Plasmodium infection in Pakistan, largely because the diversity in prevalence and species distribution of malariacausing parasites in different parts of the country has not been fully described.

This survey was conducted to provide up-to-date information on malaria prevalence throughout Pakistan. Because samples were collected from patients presenting

Table 3 Prevalence (\%) of Plasmodium infection among individuals presenting with symptoms consistent with malaria, by province and city

\begin{tabular}{|c|c|c|c|c|c|c|}
\hline \multirow[b]{2}{*}{ Province } & \multirow[b]{2}{*}{ City } & \multirow[b]{2}{*}{ Suspected cases } & \multicolumn{4}{|c|}{ Prevalence* } \\
\hline & & & P. vivax & P. falciparum & Mixed species & All species \\
\hline \multicolumn{3}{|c|}{ Khyber Pakhtunkhwa } & $234(7.7 \%)$ & $65(2.2 \%)$ & $26(1 \%)$ & $325(10.8 \%)$ \\
\hline & Bannu & 895 & $7.7 \%$ & $3.2 \%$ & $1.1 \%$ & $12.1 \%$ \\
\hline & Hangu & 445 & $6.7 \%$ & $3.1 \%$ & $1.1 \%$ & $11.0 \%$ \\
\hline & Peshawar & 720 & $6.0 \%$ & $0.4 \%$ & $0.1 \%$ & $6.5 \%$ \\
\hline & Thall & 950 & $9.7 \%$ & $2.0 \%$ & $1.1 \%$ & $12.7 \%$ \\
\hline \multirow[t]{6}{*}{ Punjab } & & & $114(2.4 \%)$ & $35(0.7 \%)$ & $8(0.2 \%)$ & 157 (3.3\%) \\
\hline & Bhakkar & 650 & $5.4 \%$ & $0.2 \%$ & $0.0 \%$ & $5.5 \%$ \\
\hline & Lahore & 980 & $1.6 \%$ & $0.0 \%$ & $0.1 \%$ & $1.7 \%$ \\
\hline & Mainwali & 1,205 & $2.6 \%$ & $2.0 \%$ & $0.3 \%$ & $4.9 \%$ \\
\hline & Muzaffarghar & 688 & $1.2 \%$ & $1.5 \%$ & $0.4 \%$ & $3.1 \%$ \\
\hline & Rawalpindi & 1,250 & $1.9 \%$ & $0.0 \%$ & $0.0 \%$ & $1.9 \%$ \\
\hline \multirow[t]{3}{*}{ Balochistan } & & & 49 (7.4\%) & $25(3.8 \%)$ & $8(1.2 \%)$ & $82(12.4 \%)$ \\
\hline & Quetta & 280 & $1.1 \%$ & $7.9 \%$ & $1.4 \%$ & $10.4 \%$ \\
\hline & Zhob & 380 & $12.1 \%$ & $0.8 \%$ & $1.1 \%$ & $13.9 \%$ \\
\hline \multirow[t]{3}{*}{ Sindh } & & & $58(10.8 \%)$ & $1(0.2 \%)$ & $1(0.2 \%)$ & $60(11.1 \%)$ \\
\hline & Hyderabad & 239 & $12.1 \%$ & $0.0 \%$ & $0.0 \%$ & $12.1 \%$ \\
\hline & Karachi & 300 & $9.7 \%$ & $0.3 \%$ & $0.3 \%$ & $10.3 \%$ \\
\hline \multirow[t]{2}{*}{ Capital } & & & 81 (4.5\%) & $2(0.1 \%)$ & $0(0.0 \%)$ & 83 (4.6\%) \\
\hline & Islamabad & 1,800 & $4.5 \%$ & $0.1 \%$ & $0.0 \%$ & $4.6 \%$ \\
\hline All & & 10,782 & $5.0 \%$ & $1.2 \%$ & $0.4 \%$ & $6.6 \%$ \\
\hline
\end{tabular}

*Prevalence was calculated by dividing the number of PCR-positive cases by the number of suspected cases. 
Table 4 Number of samples PCR-positive for Plasmodium infection, by province and city

\begin{tabular}{|c|c|c|c|c|}
\hline \multirow[b]{2}{*}{ Province } & \multirow[b]{2}{*}{ City } & \multicolumn{3}{|c|}{ PCR positive samples* } \\
\hline & & P. vivax & P. falciparum & Mixed species \\
\hline \multicolumn{2}{|c|}{ Khyber Pakhtunkhwa } & $234(72 \%)$ & $65(20 \%)$ & $26(8 \%)$ \\
\hline & Bannu & 69 & 29 & 10 \\
\hline & Hangu & 30 & 14 & 5 \\
\hline & Peshawar & 43 & 3 & 1 \\
\hline & Thall & 92 & 19 & 10 \\
\hline \multirow[t]{6}{*}{ Punjab } & & $114(73 \%)$ & $35(22 \%)$ & $8(5 \%)$ \\
\hline & Bhakkar & 35 & 1 & 0 \\
\hline & Lahore & 16 & 0 & 1 \\
\hline & Mainwali & 31 & 24 & 4 \\
\hline & Muzaffarghar & 8 & 10 & 3 \\
\hline & Rawalpindi & 24 & 0 & 0 \\
\hline \multicolumn{2}{|c|}{ Balochistan } & $49(60 \%)$ & $25(30 \%)$ & $8(10 \%)$ \\
\hline & Quetta & 3 & 22 & 4 \\
\hline & Zhob & 46 & 3 & 4 \\
\hline \multirow[t]{3}{*}{ Sindh } & & 58 (96\%) & $1(2 \%)$ & $1(2) \%$ \\
\hline & Hyderabad & 29 & 0 & 0 \\
\hline & Karachi & 29 & 1 & 1 \\
\hline \multirow[t]{2}{*}{ Capital } & & 81 (98\%) & $2(2 \%)$ & $0 \%$ \\
\hline & Islamabad & 81 & 2 & 0 \\
\hline$\overline{\text { All }}$ & & $536(76 \%)$ & $128(18 \%)$ & $43(6 \%)$ \\
\hline
\end{tabular}

* Percentages indicate the proportion of PCR-positive samples for each species.

with symptoms, one limitation is the potential for regional variation in treatment-seeking behaviour and access to treatment centres. Unfortunately, information on treatments taken prior to diagnosis was not collected and could not be included in this analysis. In addition, the timing of sample collection at each site may have coincided with varying levels of species-specific malaria transmission. All patients were sampled within the transmission season at each site, but during months that may have correlated with the presence of a particular species: $P$. vivax peaks between April and September while $P$. falciparum peaks between August and December [2,34-36]. Regional variations in peak times also occur, with a study in the hilly region of Balochistan reporting highest $P$. vivax infection and lowest $P$. falciparum infection in March and the opposite pattern in October [37]. These effects should be taken into account when assessing relatively small reported differences in the prevalence of malaria and in the proportion of $P$. vivax and $P$. falciparum cases among regions. Despite these limitations, the data presented here contribute to a more comprehensive and current characterization of malaria in Pakistan than has previously been available.

The predominance of malaria infection in males in their twenties has been observed in previous studies in this region $[37,38]$. Some hypotheses for the disproportionate number of male malaria patients include increased exposure because males are more likely to work outside and not be as well-covered as females, leading to an increased number of infected Anopheles bites, or that females may have diminished access to health care facilities and may not seek medical attention as frequently as males [26].

This survey indicated that the highest prevalence of malaria is found in Balochistan, followed by Sindh and Khyber Pakhtunkhwa, with lower prevalence in Punjab and the city of Islamabad. Similarly, the Malaria Case Management Desk Guide reported in 2007 that Sindh and Balochistan provinces contributed the majority of malaria cases in Pakistan, followed by Khyber Pakhtunkhwa province and the Federally Administered Tribal Areas, with the fewest cases reported in Punjab province [34]. This study also confirmed previous findings that $P$. vivax and $P$. falciparum are the two major Plasmodium species found in Pakistan, with $P$. vivax predominating in most regions $[13,33,39]$.

In addition to the highest malaria prevalence in Pakistan, Balochistan also had the highest proportion of P. falciparum cases, due to the predominance of falciparum malaria in one of its districts, Quetta. Other studies have also reported a high prevalence of $P$. falciparum in this region, including in Quetta itself $[39,40]$, and the cities of Zhob [37], East Balochistan [39], and Khuzdar in Balochistan province [41]. Although generally higher than in other regions of Pakistan, estimates of the proportion of $P$. falciparum infections within Balochistan province vary widely by location, from $15 \%$ in Zhob to nearly $90 \%$ in Quetta, indicating that geographic variation among districts is high.

The two sites in Sindh, Karachi and Hyderabad, had an overall malaria prevalence of $11 \%$, with very few $P$. falciparum or mixed species infections. In contrast, previous studies have shown that approximately one-quarter to onehalf of malaria cases were attributed to $P$. falciparum in these cities [42-44]. This difference may be attributable to the narrow sampling window in this province. The majority of samples was collected in April in Sindh, while previous observations indicate that peak infection of P. falciparum does not occur until later in the year [32].

Thall, Bannu and Hangu in Khyber Pakhtunkhwa province all showed high prevalence of malaria and a high proportion of cases attributed to P. falciparum. Other studies in this region have found a relatively high number of cases and varying levels of $P$. falciparum, from $16 \%$ of malaria cases in Buner [42] to $25 \%$ in Abbottabad and Bannu [33,45] to over $90 \%$ of cases in Manshera [46]. Cross-border migration may have contributed to the maintenance or surge of malaria in this region. Between 1979 and 1982, refugees from Afghanistan fled across the border into Khyber Pakhtunkhwa and Balochistan provinces [47]. 
This influx of a potentially more malaria-susceptible population may have overwhelmed the public health system [24], leading to greater disease. The movement of Afghan refugees into Baluchestan province, Iran, was estimated to result in a $24-36 \%$ increase in the number of malaria cases [48]. Recent internal displacement may also be contributing to the high prevalence of malaria. In 2009, inhabitants of several districts in the Federally Administered Tribal Areas and Khyber Pakhtunkhwa fled war conditions to settle in adjoining districts $[49,50]$. These large movements of vulnerable populations may have altered the distribution of malaria and malaria-susceptible people in the country [50], contributing to epidemics such as that reported in a Pakistani refugee camp in 2003 where incidence was as high as 100 cases per 1,000 persons per year [51].

Punjab province and the city of Islamabad had little malaria in comparison with other parts of the country. The prevalence of malaria in Islamabad has not previously been reported, but other studies in Punjab province reported similar results, with a microscopy-positive malaria prevalence of $2.4 \%$ in house-to-house surveys in 1999 [52] and low annual incidence, with less than one case per 10,000 per year between 2004 and 2009 [4]. Two contributors to the low level of malaria in Punjab have been suggested. Environmental changes resulting in waterlogging and salinization may have reduced suitable habitats for the more efficient vector, Anopheles culicifacies, while increasing breeding sites for the salt tolerant and less efficient vector, Anopheles stephensi [4]. Additionally, overall socio-economic conditions and the public health infrastructure are comparatively better in Punjab than in the rest of the country, and may play a role in more effectively controlling malaria [52].

Agreement between PCR and microscopy was high overall, but discrepancies were detected in samples that were microscopy-positive and PCR negative for Plasmodium and for samples that were P. falciparum or P. vivax monoinfections by microscopy but mixed species infections by PCR. Confirmation of PCR results in repeated assays suggests that the error likely lies in diagnosis by microscopy. Similar results have been reported in Pakistan [33] where nearly $15 \%$ of samples positive by microscopy were parasite-negative by PCR and in a 2007 study in Afghanistan, Iran, and Pakistan where 6.5, 2.2 and 23.5\% of microscopically diagnosed $P$. vivax mono-infections, respectively, were mixed species by PCR [53]. The propensity to report febrile patients as parasite-positive has been reported [54], and factors influencing accuracy of microscopic diagnosis, including use of contaminated reusable microscope slides, staining artifacts, lack of microscopic expertise, and lack of quality assurance $[55,56]$ have been well-documented.

It has been estimated that in countries where $P$. vivax is predominant, over one-third of patients presenting with acute $P$. vivax also harbour cryptic $P$. falciparum [57]. Misdiagnosis of mixed species infections can result in improper or incomplete treatment, particularly in countries like Pakistan, where chloroquine is used to treat $P$. vivax but is known to be ineffective against P. falciparum. Household surveys conducted in 2010 indicating that $80 \%$ of patients with suspected $P$. falciparum malaria (confirmed or unconfirmed) received chloroquine, 14\% received an artemisinin-based combination therapy (ACT) and $16 \%$ were not treated with any anti-malarial [32]. Assessment of the quality of malaria microscopy in Pakistan may aid in identifying areas for improved diagnosis and treatment, particularly in regions endemic for both Plasmodium species.

\section{Conclusions}

Pakistan faces several challenges in the management and control of malaria, including misdiagnosis, lack of diagnostic facilities, use of presumptive treatments and unavailability of ACT [58-60]. Information on the burden and species distribution of malaria is critical for guiding national and provincial efforts in diagnosis and effective treatment. The results of this study indicate that malaria control efforts should be focused on Khyber-Pakhtunkhwa, Balochistan and Sindh provinces, where malaria prevalence is highest, with an emphasis on improving species diagnosis and ACT availability for treatment of P. falciparum in Quetta city of Balochistan, parts of Khyber Pakhtunkhwa, and Punjab province.

\section{Competing interests}

The authors declare that they have no competing interests.

\section{Authors' contributions}

AAK designed the study, carried out the laboratory experiments, and conducted data analysis. AAK and MV drafted the manuscript. MFN, HSS and AY participated in sample and data collection and microscopy. KS aided in laboratory experimental design and execution. MV, LK, SAM and CVP provided guidance and coordination for study design laboratory analyses and data analysis, and edited and revised the manuscript. All authors read and approved the final manuscript.

\section{Acknowledgements}

The authors thank the study participants for their involvement in the study. The authors also thank Matthew Adams, Malathi Vadla and Sudhaunshu Joshi at the University of Maryland for their technical assistance and Muhammad Shahid, Islamil Jalil, Ifthikhar Ahmed, Adeel Riaz and Noor Rehman in Pakistan for helping in sample collection. This work was supported by a grant from the Higher Education Commission of Pakistan in support of AAK's PhD studies at Quaid-i-Azam University, Islamabad, Pakistan, and was supported in part by the Howard Hughes Medical Institute / Center for Vaccine Development at the University of Maryland School of Medicine, Baltimore, MD, USA.

\section{Author details}

${ }^{1}$ Department of Biochemistry, Faculty of Biological Sciences, Quaid-i-Azam University, Islamabad, Pakistan. ${ }^{2}$ Howard Hughes Medical Institute/Center for Vaccine Development, University of Maryland School of Medicine, Baltimore, MD, USA. ${ }^{3}$ WorldWide Antimalarial Resistance Network Molecular Module, University of Maryland School of Medicine, Baltimore, MD, USA. ${ }^{4}$ King Edward Medical University, Lahore, Pakistan. ${ }^{5}$ Department of Biochemistry and Molecular Biology, University of Gujrat, Gijrat, Pakistan. 
Received: 30 May 2013 Accepted: 26 August 2013

Published: 28 August 2013

\section{References}

1. WHO: WHO Eastern Mediterranean regional office. Cairo: World Health Organization; 2013

2. Williams O, Meek S: Malaria: country profiles. London: Department of International Development; 2011

3. Mukhtar M: Killer number one: the fight against malaria: malaria strategy lags behind the global goals, Humanitarian news and analysis a service of the UN Office for the Coordination of Humanitarian Affairs. Nairobi: IRIN; 2006.

4. Kakar Q, Khan MA, Bile KM: Malaria control in Pakistan: new tools at hand but challenging epidemiological realities. East Mediterr Health J 2010, 16(Suppl):S54-S60.

5. Federal Research Division: Country profile: Pakistan. Library of Congress; 2012.

6. Land surface elevation extremes by country. http://en.wikipedia.org/wiki/ List_of_elevation_extremes_by_country.

7. WHO: World malaria report 2012. Geneva; 2012

8. Kakar Q, Khan MA, Bile KM: Malaria control in Pakistan: new tools at hand but challenging epidemiological realities. East Mediterr Health J 2010, 16(Suppl):S54-S60.

9. Bouma MJ, Dye C, van der Kaay HJ: Falciparum malaria and climate change in the northwest frontier province of Pakistan. Am J Trop Med Hyg 1996, 55:131-137.

10. Bouma MJ, Parvez SD, Nesbit R, Winkler AM: Malaria control using permethrin applied to tents of nomadic Afghan refugees in northern Pakistan. Bull World Health Organ 1996, 74:413-421.

11. Rab MA, Freeman TW, Durrani N, De PD, Rowland MW: Resistance of Plasmodium falciparum malaria to chloroquine is widespread in eastern Afghanistan. Ann Trop Med Parasitol 2001, 95:41-46.

12. Durrani AB, Durrani IU, Abbas N, Jabeen M: Epidemiology of cerebral malaria and its mortality. J Pak Med Assoc 1997, 47:213-215.

13. WHO: World malaria report. Geneva: World Health Organization; 2011.

14. Nizamani MA, Kalar NA, Khushk IA: Burden of malaria in Sindh, Pakistan: a two years surveillance report. J Liaquat University of Med Health Sci 2006, 5:762-83.

15. Ghanchi NK, Ursing J, Beg MA, Veiga MI, Jafri S, Martensson A: Prevalence of resistance associated polymorphisms in Plasmodium falciparum field isolates from southern Pakistan. Malar J 2011, 10:18.

16. Rana MS, Tanveer A: Chloroquine resistance and Plasmodium falciparum in Punjab, Pakistan during 2000-2001. Southeast Asian J Trop Med Public Health 2004, 35:288-291.

17. Robinson DS, Hadley-Brown M, Ejele OA, Robinson PS: Chloroquine-resistant malaria in Pakistan. Lancet 1984, 2:987.

18. Rawasia WF, Sridaran S, Patel JC, Abdallah J, Ghanchi NK, Barnwell JW, Escalante AA, Udhayakumar V, Beg MA: Genetic backgrounds of the Plasmodium falciparum chloroquine resistant transporter (pfcrt) alleles in Pakistan. Infect Genet Evol 2012, 12:278-281.

19. Parikh R, Amole I, Tarpley M, Gbadero D, Davidson M, Vermund SH: Cost comparison of microscopy vs. empiric treatment for malaria in Southwestern Nigeria: a prospective study. Malar J 2010, 9:371.

20. Malik IA, Iqbal I, Malik S: A study of cerebral malaria at Multan. Pakistan Pediatric J 1996, 20:175-180.

21. Murtaza G, Memon IA, Noorani AK: Malaria prevalence in Sindh. Med Channel 2004, 10:41-42

22. Sheikh AS, Sheikh AA, Sheikh NS, Paracha SM: Endemicity of malaria in Quetta. Pakistan J Med Res 2005, 44:41-45.

23. Howard N, Durrani N, Sanda S, Beshir K, Hallett R, Rowland M: Clinical trial of extended-dose chloroquine for treatment of resistant falciparum malaria among Afghan refugees in Pakistan. Malar J 2011, 10:171.

24. Suleman M: Malaria in Afghan refugees in Pakistan. Trans $R$ Soc Trop Med Hyg 1988, 82:44-47.

25. De ZJ, Mujtaba SM, Shah IH: Malaria control and long-term periodicity of the disease in Pakistan. Trans R Soc Trop Med Hyg 1980, 74:624-632.

26. Khan HU, Khattak AM, Khan MH, Mahsud IU, Shah SH: A study of prevalence of malaria in adult population of D. I. Khan, Pakistan. Biomedica 2006, 22:99-104.

27. Nawaz S: FATA—A most dangerous place. D.C: Washington; 2009

28. Asif SA: Departmental audit of malaria control programme 2001-2005 north west frontier province (NWFP). J Ayub Med Coll Abbottabad 2008, 20:98-102.
29. Snounou G, Viriyakosol S, Zhu XP, Jarra W, Pinheiro L, De Rosario VE, Thaithong S, Brown KN: High sensitivity of detection of human malaria parasites by the use of nested polymerase chain reaction. Mol Biochem Parasitol 1993, 61:315-320.

30. Singh N, Shukla MM, Sharma VP: Epidemiology of malaria in pregnancy in central India. Bull World Health Organ 1999, 77:567-572.

31. Qayum M, Zahur H, Ahmad N, llyas M, Khan A, Khan S: SPHERE-based assessment of knowledge and preventive measures related to malaria among the displaced population of Jalozai, Pakistan. J Pak Med Assoc 2012, 62:344-346.

32. MOH: Pakistan national strategic plan for malaria control 2010 - 2015. Islamabad: Ministry of Health; 2010.

33. Khatoon L, Baliraine FN, Bonizzoni M, Malik SA, Yan G: Prevalence of antimalarial drug resistance mutations in Plasmodium vivax and P. falciparum from a malaria-endemic area of Pakistan. Am J Trop Med Hyg 2009, 81:525-528.

34. DMC: Malaria case management desk guide for clinicians and health care providers. Islamabad: Directorate of Malaria Control; 2007.

35. Khatoon L, Baliraine FN, Bonizzoni M, Malik SA, Yan G: Genetic structure of Plasmodium vivax and Plasmodium falciparum in the Bannu district of Pakistan. Malar J 2010, 9:112

36. Mukhtar M: Guidelines for antivector interventions for monsoon season. Pakistan: Directorate of Malaria Control, Ministry of Health; 2009:1-14.

37. Yasinzai MI, Kakarsulemankhel JK: Incidence of human malaria infection in northern hilly region of Balochistan, adjoining with NWFP, Pakistan: district Zhob. Pak J Biol Sci 2008, 11:1620-1624.

38. Yasinzai Ml, Kakarsulemankhel JK: Prevalence of human malaria infection in Pakistani areas bordering with Iran. J Pak Med Assoc 2013, 63:313-316.

39. Yasinzai MI, Kakarsulemankhel JK: Prevalence of human malaria infection in bordering areas of East Balochistan, adjoining with Punjab: Loralai and Musakhel. J Pak Med Assoc 2009, 59:132-135.

40. Yasinzai MI, Kakarsulemankhel JK: Frequency of human malaria infection in south east area of Balochistan, District Lasdella. Pak J Biol Sci 2012, 28:167-170.

41. Farooq MA, Salamat A, Iqbal MA: Malaria-an experience at CMH Khuzdar (Balochistan). J Coll Physicians Surg Pak 2008, 18:257-258.

42. Noor $\mathrm{M}, \mathrm{Akbar} \mathrm{H}$ : Prevalence of malaria in general populationof distric Buner. J Pak Inst Med Sci 2003, 17:75-80.

43. Beg MA, Sani N, Mehraj V, Jafri W, Khan MA, Malik A, Menezes E, Hussain R, Smego R Jr: Comparative features and outcomes of malaria at a tertiary care hospital in Karachi, Pakistan. Int J Infect Dis 2008, 12:37-42.

44. Hayyat AS, Memon F, Shaikh N, Fatah Dero AF: Incidence and pattern of malarial infection at a tertiary care Hospital of Hyderabad. World J Med Sci 2009, 4:9-12.

45. Idris M, Sarwar J, Fareed J: Pattern of malarial infection diagnosed at Ayub teaching hospital Abbottabad. J Ayub Med Coll Abbottabad 2007, 19:35-36.

46. Jalal UD, Khan SA, Ally SH: Malaria in children: study of 160 cases at a private clinic in Mansehra. J Ayub Med Coll Abbottabad 2006, 18:44-45.

47. WHO: World malaria situation in 1990. Bull World Health Organ 1992, 70:801-813.

48. Basseri HR, Raeisi A, Holakouie K, Shanadeh K: Malaria prevention among Afghani refugees in a malarious area, southeastern Iran. Bull Soc Pathol Exot 2010, 103:340-345.

49. Kakar Q: Guidelines for anti-vector interventions in complex emergencies/IDPs. Islamabad: Directorate of Malaria Control, Ministry of Health; 2009.

50. WFP: U.S Global Health Policy. California: U.S. Global Health Programs; 2009.

51. Leslie T, Kaur H, Mohammed N, Kolaczinski K, Ord RL, Rowland M: Epidemic of Plasmodium falciparum malaria involving substandard antimalarial drugs, Pakistan, 2003. Emerg Infect Dis 2009, 15:1753-1759.

52. Herrel N, Amerasinghe FP, Ensink J, Mukhtar M, van der Hoek W, Konradsen F: Adult anopheline ecology and malaria transmission in irrigated areas of South Punjab, Pakistan. Med Vet Entomol 2004, 18:141-152.

53. Zakeri S, Kakar Q, Ghasemi F, Raeisi A, Butt W, Safi N, Afsharpad M, Memon MS, Gholizadeh S, Salehi M, Atta H, Zamani G, Djadid ND: Detection of mixed Plasmodium falciparum \& P. vivax infections by nested-PCR in Pakistan, Iran \& Afghanistan. Indian J Med Res 2010, 132:31-35.

54. Ngasala B, Mubi M, Warsame M, Petzold MG, Massele AY, Gustafsson LL, Tomson G, Premji Z, Bjorkman A: Impact of training in clinical and microscopy diagnosis of childhood malaria on antimalarial drug prescription and health outcome at primary health care level in Tanzania: a randomized controlled trial. Malar J 2008, 7:199. 
55. Makler MT, Palmer CJ, Ager AL: A review of practical techniques for the diagnosis of malaria. Ann Trop Med Parasitol 1998, 92:419-433.

56. Moody A: Rapid diagnostic tests for malaria parasites. Clin Microbiol Rev 2002, 15:66-78.

57. Looareesuwan S, White NJ, Chittamas S, Bunnag D, Harinasuta T: High rate of Plasmodium vivax relapse following treatment of falciparum malaria in Thailand. Lancet 1987, 2:1052-1055.

58. GFATM: Round 7 funding application: Pakistan 2007. Washington, DC: The Global Fund; 2007.

59. SoSec Consulting Services: 19 districts Pakistan (draft final report). Islamabad: Islamabad SoSec Consulting Services; 2009.

60. Rowland M, Rab MA, Freeman T, Durrani N, Rehman N: Afghan refugees and the temporal and spatial distribution of malaria in Pakistan. Soc Sci Med 2002, 55:2061-2072.

doi:10.1186/1475-2875-12-297

Cite this article as: Khattak et al.: Prevalence and distribution of human

Plasmodium infection in Pakistan. Malaria Journal 2013 12:297.

\section{Submit your next manuscript to BioMed Central and take full advantage of:}

- Convenient online submission

- Thorough peer review

- No space constraints or color figure charges

- Immediate publication on acceptance

- Inclusion in PubMed, CAS, Scopus and Google Scholar

- Research which is freely available for redistribution 